(2) Open Access Full Text Article

\title{
Impact of potential pregabalin or duloxetine drug-drug interactions on health care costs and utilization among Medicare members with fibromyalgia
}

\author{
This article was published in the following Dove Press journal: \\ ClinicoEconomics and Outcomes Research \\ 14 October 2014 \\ Number of times this article has been viewed
}

Jeffrey J Ellis'

Alesia B Sadosky²

Laura LTen Eyck'

Joseph C Cappelleri

Courtney R Brown ${ }^{3}$

Brandon T Suehs'

Bruce Parsons ${ }^{2}$

'Comprehensive Health Insights Inc., Louisville, KY, USA; 'Pfizer Inc., New York, NY, USA; ${ }^{3}$ Humana Inc., Louisville, KY, USA
Correspondence: Jeffrey J Ellis Comprehensive Health Insights Inc. 325 West Main Street, WFP6W, Louisville, KY, USA 40202

Tel +l 7343974610

Fax + I 9203397736

Email jellis2।@humana.com
Purpose: To examine the impact of newly initiated pregabalin or duloxetine treatment on fibromyalgia (FM) patients' encounters with potential drug-drug interactions (DDIs), the health care cost and utilization consequences of those interactions, and the impact of treatment on opioid utilization.

Patients and methods: Subjects included those with an FM diagnosis, a pregabalin or duloxetine prescription claim (index event), $\geq 1$ inpatient or $\geq 2$ outpatient medical claims, and $\geq 12$ months preindex and $\geq 6$ postindex enrollment. Propensity score matching was used to help balance the pregabalin and duloxetine cohorts on baseline demographics and comorbidities. Potential DDIs were defined based on Micromedex 2.0 software and were identified by prescription claims.

Results: No significant differences in baseline characteristics were found between matched pregabalin $(\mathrm{n}=794)$ and duloxetine cohorts $(\mathrm{n}=794)$. Potential DDI prevalence was significantly greater $(P<0.0001)$ among duloxetine subjects $(71.9 \%)$ than among pregabalin subjects $(4.0 \%)$. There were no significant differences in all-cause health care utilization or costs between pregabalin subjects with and without a potential DDI. By contrast, duloxetine subjects with a potential DDI had higher mean all-cause costs $(\$ 9,373$ versus $\$ 7,228 ; P<0.0001)$ and higher mean number of outpatient visits/member (16.0 versus $13.0 ; P=0.0009)$ in comparison to duloxetine subjects without a potential DDI. There was a trend toward a statistically significant difference between pregabalin and duloxetine subjects in their respective pre- versus post-differences in use of $\geq 1$ long-acting opioids ( $1.6 \%$ and $3.4 \%$, respectively; $P=0.077)$.

Conclusion: The significantly higher prevalence of potential DDIs and potential cost impact found in FM duloxetine subjects, relative to pregabalin subjects, underscore the importance of considering DDIs when selecting a treatment.

Keywords: Cymbalta, morphine equivalents, Lyrica

\section{Introduction}

Difficult to diagnose and a painful experience for patients, fibromyalgia (FM) is a musculoskeletal disease with a large number of symptoms and a record of only partial treatment success. ${ }^{1,2}$ Recent studies have estimated the prevalence of FM in the United States to range from an age- and sex-adjusted prevalence of $6.4 \%{ }^{3}$ to an age-, sex-, and race-adjusted prevalence of $9.5 \%{ }^{4}$ FM presents more often in women than men $(9: 1) ;^{5}$ however, the difference is linked to the decreased number of tender points found in men, and the prevalence ratio decreases to $3: 1$ if the definition is broadened to "chronic widespread pain syndrome". ${ }^{6}$ The most common symptom of this disease is described by 
patients as a penetrating burning ache located at various areas in the body. ${ }^{7,8}$ In addition to the pervasive pain often reported by patients, other concomitant symptoms often include cognitive defects, sleep disturbance, fatigue, and soreness of joints, muscles, and tendons. ${ }^{9}, 10$ The American College of Rheumatology has recently updated its clinical case definition of FM based on the widespread pain index (WPI) and a symptom severity (SS) scale, with a FM diagnosis defined as either 1 ) a WPI $\geq 7$ and $\mathrm{SS} \geq 5$; or 2 ) a WPI $3-6$ and $\mathrm{SS} \geq 9 .{ }^{11}$

Treatment considerations for patients with FM are complex due to the concomitant disease states often experienced by these patients. For example, there is a two- to sevenfold increase in the possibility patients with FM will present with chronic fatigue syndrome, irritable bowel syndrome, rheumatic conditions, anxiety, and depression. ${ }^{11,12}$ These conditions, along with possible impaired cognition and decision making, impose a major burden of illness on FM patients. Although nonpharmacologic therapies have been shown to significantly improve FM symptoms, they are less preferred by patients than drug alternatives. ${ }^{13,14}$ Several guidelines have been published to guide pharmacological treatment of FM. ${ }^{15-19}$ Additionally, while opioid use for FM-associated pain control is seen in clinical practice, the use of chronic opioid therapy is not recommended due to the clinical and societal consequences, ${ }^{20}$ with the most recent guidelines discouraging use of strong opioids. ${ }^{17-19}$

Only three drugs have been approved by the Food and Drug Administration (FDA) for treatment of FM: pregabalin (2007), duloxetine (2008), and milnacipran (2009). All three agents have received a strong recommendation for use in FM from the more recent pharmacological treatment guidelines ${ }^{16-19}$ and a modest evidence for efficacy rating from the older American Pain Society 2005 guideline. ${ }^{15}$ No head-to-head comparative trials of the three FDA-approved FM treatments have been conducted. A recent meta-analysis of eleven randomizedcontrolled trials indirectly compared the benefits, harms, and adverse event-related study withdrawal of pregabalin, duloxetine, and milnacipran. ${ }^{21}$ Adjusted indirect comparisons revealed no significant differences between the three drugs for achieving 30\% pain relief and study withdrawal due to adverse events. ${ }^{21}$ Significant differences were found across the three drugs at the symptom level and side effect level. For example, duloxetine was superior to milnacipran and pregabalin in improving depressed mood, whereas milnacipran and pregabalin were superior to duloxetine in alleviating fatigue. ${ }^{21}$ Duloxetine had a higher risk of headache, nausea, and diarrhea compared to pregabalin. ${ }^{21}$ The authors of this meta-analysis conclude, similarly to the aforementioned pharmacological guidelines, that drug therapy selection should be based on symptomology, concomitant comorbidities, drug adverse effect profiles, and patient preference. ${ }^{21}$ Furthermore, drug-drug interactions (DDIs) due to the number of possible comorbid conditions also being treated pose a significant challenge to providers with regard to choosing the most appropriate FM medication for their patients.

Within a population of patients taking pregabalin or duloxetine, there is a paucity of data regarding the real-world prevalence of potential DDIs, the economic and clinical impact of those interactions, and the potential opioid-sparing effect from taking pregabalin or duloxetine instead of opioid agents. To address this gap in knowledge, this study examines the impact of newly initiated pregabalin or duloxetine treatment on FM patients' encounters with potential DDIs, the health care cost and utilization consequences of those interactions, and on opioid utilization.

\section{Methods}

\section{Study design and subject selection}

The research protocol was reviewed and approved prior to study initiation by an independent Institutional Review Board and was granted a waiver of informed consent and a waiver of authorization to use protected health information.

This study is a retrospective, matched cohort study using medical and pharmacy claims collected from a large Medicare Advantage Prescription Drug (MAPD) health plan. Medical and pharmacy claims data collected between January 1, 2007 and December 31, 2012 were utilized. The index date was defined as the date of the first prescription fill for pregabalin or duloxetine with no use in the prior 12 months (to classify subjects as new initiators). Index prescriptions were identified between January 1, 2008 and June 30, 2012. Milnacipran was not included as a comparator, as the study period did not allow for sufficient sample size to analyze those patients.

Study subjects were MAPD members who were diagnosed with FM identified by International Classification of Disease, 9th revision, Clinical Modification (ICD-9-CM) codes. To be included in the study, subjects were required to meet all of the following criteria: at least one prescription claim for pregabalin or duloxetine between January 1, 2008 and June 30, 2012, and diagnosis for FM (729.1) in any position on one or more inpatient medical claims or two or more outpatient medical claims observed during the observation period (January 1, 2007 to December 31, 2012) with at least one claim within 90 days of the index date. Subjects with any of the following were excluded from the analysis: age $<18$ 
or $>89$ years; continuous enrollment $<12$ months preindex or $<6$ months postindex; diagnosis of diabetic peripheral neuropathy at any time after the index date; diagnosis and/or procedure indicative of pregnancy, cancer, or transplant surgery during study period; residence in a long-term care facility $\geq 90$ days during the study period; or one or more prescription claims for the nonindex comparator drug (eg, if index drug is duloxetine, then nonindex comparator drug is pregabalin) 12 months prior to or on the index date.

\section{Baseline measures}

The medication filled on a subject's index date determined the subject's assignment to either the pregabalin cohort or the duloxetine cohort. Age was calculated as of the index date. Sex and race/ethnicity were obtained from enrollment data. Geographic region was based on the subject's state of residence on the index date. Low-income subsidy status, defined as Medicare beneficiaries with income below $150 \%$ of poverty level, and Medicare dual eligibility status were obtained from enrollment data and based on status on the index date. Comorbidity burden was measured by the Deyo-Charlson Comorbidity Index (DCCI). The DCCI uses 17 categories of comorbidity to calculate a score that reflects cumulative increased likelihood of 1-year mortality. ${ }^{22,23}$ It is based on ICD-9 diagnoses and procedure codes and their associated weights. The DCCI score can range from 0 to 33 , with higher scores indicating increased disease burden and an increased likelihood of 1-year mortality. Several pain-related comorbid medical conditions were identified by the presence of at least one medical claim with an ICD-9-CM diagnosis code for the comorbidity in any diagnosis code position.

Preindex and postindex opioid utilization (any claims, one claim, and two or more claims) was defined as one or more prescription fills during the respective observation period. Opioids were categorized as long-acting, short-acting less potent, and short-acting more potent. ${ }^{24}$ Further, all oral and transdermal opioids were converted to morphine equivalents (MEq) based on conversion factors. ${ }^{24}$ The opioid dose strength and quantity of fill for each adjudicated (ie, insurer payment determined) opioid prescription claim was converted to $\mathrm{MEq}$ and summed for the respective observation period. Morphine equivalents for each member were then normalized to an average $\mathrm{MEq}$ per 30 days.

\section{Study outcomes Drug-drug interaction status} Medications with high potential for DDI with duloxetine or pregabalin (Table 1) were identified based on a drug interaction report generated from Micromedex 2.0 (Truven Health Analytics Inc., Greenwood Village, CO, USA). Interactions classified as contraindicated, major, or moderate were included, whereas minor or unknown interactions were not included. Prescription claims records were used to identify subjects using medication(s) that potentially interact with the index medication. Subjects were flagged as having a potential DDI if they had one or more of the following: A prescription claim observed for the interaction medication during the preindex period and a corresponding days' supply indicative of coverage that overlapped the index date; or an adjudicated prescription claim for an interacting medication filled within 30 days after the index date.

\section{Health care resource utilization and costs}

All-cause medical service utilization and costs were identified using medical claims. Place of service was used to distinguish inpatient, emergency room, physical therapy (PT), or non-PT outpatient utilization and costs. Total pharmacy costs were defined as the sum of costs associated with all adjudicated pharmacy claims. Total all-cause health care costs were defined as the sum of the respective total medical cost and total pharmacy cost components. All cost calculations included both member and plan paid components. Postindex opioid utilization was determined both categorically and as MEq per 30 days as previously described for the preindex period.

\section{Analysis}

Propensity score (PS) matching was utilized to reduce selection bias in this nonrandomized, observational study. ${ }^{25,26}$ All baseline demographic characteristics and comorbidities present were included in the PS matching process. The PS matching process, matching a duloxetine member to a pregabalin member, was based on the nearest neighbor approach, without replacement, and utilized a caliper width of 0.005 . Diagnostic evaluations to examine balance in preindex covariates (from the PS model) between matched treatment groups were considered. Means, standard deviations, medians, and interquartile ranges were calculated for continuous measures. Comparisons for preindex continuous measures were performed using Wilcoxon rank-sum tests. Counts and percentages were calculated for categorical data. Preindex categorical comparisons were evaluated using chi-square tests. Wilcoxon rank-sum test and chi-square tests were also performed for postindex outcomes. $^{27}$ 
Table I Pregabalin and duloxetine drug-drug interactions

\begin{tabular}{|c|c|c|}
\hline Severity & $\begin{array}{l}\text { Brief description of potential harm } \\
\text { due to DDI }\end{array}$ & Interacting drug \\
\hline \multicolumn{3}{|l|}{ Pregabalin } \\
\hline Major & Reduced pregabalin effectiveness & naproxen, ketorolac \\
\hline \multicolumn{3}{|l|}{ Duloxetine } \\
\hline \multirow[t]{4}{*}{ Contraindicated } & CNS toxicity or serotonin syndrome & $\begin{array}{l}\text { isocarboxazid, linezolid, procarbazine, rasagiline, selegiline, } \\
\text { tranylcypromine }\end{array}$ \\
\hline & $\begin{array}{l}\text { Increased serum concentrations of interacting } \\
\text { drug and risk of cardiac arrhythmia }\end{array}$ & thioridazine \\
\hline & $\begin{array}{l}\text { Increased risk of extrapyramidal reactions or } \\
\text { neuroleptic malignant syndrome }\end{array}$ & metoclopramide \\
\hline & $\begin{array}{l}\text { Increased risk of serotonin syndrome or } \\
\text { neuroleptic malignant syndrome-like reactions }\end{array}$ & methylene blue \\
\hline \multirow[t]{5}{*}{ Major } & $\begin{array}{l}\text { Increased interacting drug plasma level and } \\
\text { increased risk of QT prolongation }\end{array}$ & clozapine \\
\hline & Increased risk of bleeding & antiplatelet agents, escitalopram \\
\hline & Increased risk of serotonin syndrome & $\begin{array}{l}\text { almotriptan, citalopram, cyclobenzaprine, desvenlafaxine, } \\
\text { dextromethorphan, eletriptan, fluoxetine, fluvoxamine, frovatriptan, } \\
\text { hydroxytryptophan, lithium, lorcaserin, methadone, milnacipran, } \\
\text { naratriptan, paroxetine, rizatriptan, sertraline, sumatriptan, } \\
\text { tapentadol, tramadol, trazodone, tryptophan, venlafaxine, zolmitriptan }\end{array}$ \\
\hline & $\begin{array}{l}\text { Increased risk of serotonin syndrome or } \\
\text { neuroleptic malignant syndrome-like reactions }\end{array}$ & vilazodone \\
\hline & $\begin{array}{l}\text { Increased serum concentrations of interacting } \\
\text { drugs and an increased risk of cardiotoxicity }\end{array}$ & Class IC antiarrhythmic agents \\
\hline \multirow[t]{4}{*}{ Moderate } & $\begin{array}{l}\text { Decreased plasma concentrations of the active } \\
\text { metabolites of interacting drug }\end{array}$ & tamoxifen \\
\hline & $\begin{array}{l}\text { Increased duloxetine serum concentrations } \\
\text { and risk of adverse effects }\end{array}$ & ciprofloxacin, clobazam, enoxacin, mirabegron, quinidine \\
\hline & $\begin{array}{l}\text { Increased exposure to interacting drug and } \\
\text { potential toxicity }\end{array}$ & phenothiazines, tamsulosin, tricyclic antidepressants \\
\hline & Increased risk of bleeding & $\begin{array}{l}\text { acenocoumarol, dabigatran, dalteparin, danaparoid, desirudin, } \\
\text { enoxaparin, fondaparinux, nonsteroidal anti-inflammatory agents, } \\
\text { phenindione, phenprocoumon, tinzaparin, warfarin }\end{array}$ \\
\hline
\end{tabular}

Notes: Reprinted with permission. Source: Micromedex 2.0 (Truven Health Analytics Inc.), accessed May 31, 2013. Copyright I974-20I4 Truven Health Analytics Inc. All rights reserved. Drugs with primary use in the hospital setting (eg, lepirudin) were excluded.

The relationship between the presence of a potential DDI and health care costs was examined in more detail via fitting of a multivariable statistical model $1 .^{28} \mathrm{~A}$ generalized linear mixed model (GLMM) with a gamma distribution and log link was fitted to model all-cause total health care costs. The GLMM was adjusted for the presence of a potential DDI, index drug used ("Drug"), DDI*drug interaction term, baseline demographic characteristics, baseline comorbidities present, and preindex medication utilization. Model-based means and confidence intervals were derived from the models and retransformed into dollar values through exponentiation of the least square (LS) means estimates. All comparisons of total all-cause health care costs between and within cohorts were assessed using Wald chi-square tests.

Differences in all-cause total health care costs were compared between the cohorts (ie, by pregabalin/duloxetine and DDI status) via difference-in-differences (DID) analyses, utilizing the model-based LS means estimates and corresponding standard errors, as follows:

$$
\begin{aligned}
\mathrm{DID}= & (\text { DDI present }- \text { DDI absent in the pregabalin } \\
& \text { cohort })-(\text { DDI present }- \text { DDI absent in the } \\
& \text { duloxetine cohort }) .
\end{aligned}
$$

Two-sample $t$-tests were performed to formally test the DID values for statistical significance.

Differences in preindex and postindex opioid utilization and MEq were compared between pregabalin and duloxetine cohorts via DID analysis. The $t$-statistic for the opioid utilization DID analysis was derived from a GLMM with a logit link and binary distribution adjusting for baseline demographics, DCCI, and pre- and postindex nonopioid pain medication utilization. The $t$-statistic for the MEq DID analysis was derived from a GLMM with an identity link and a Gaussian distribution adjusting for baseline demographics, DCCI, and pre- and postindex nonopioid 
pain medication utilization. The MEq DID analysis spanned opioid prescription claims from 6 months preindex and 6 months postindex.

All data analyses were conducted using SAS version 9.3/ SAS Enterprise Guide 5.1 (SAS Institute, Inc., Cary, NC, USA). The a priori alpha level for all inferential analyses was set at 0.05 , and all statistical tests were two-tailed.

\section{Results}

\section{Patient characteristics}

A total of 2,965 subjects met the study inclusion and exclusion criteria (pregabalin $n=839$, duloxetine $n=2,126$ ). The PS matching process resulted in 794 matched pairs $(1,588$ total study subjects). The lack of statistically significant differences between the two matched cohorts in the distributions of baseline demographics (Table 2 ) or preindex comorbidity measures (Table 3) provides evidence to support that the matching was successful.

\section{Potential DDIs}

Thirty-two subjects $(4.0 \%)$ in the pregabalin cohort were identified as having one or more potential DDIs present during the 6-month postindex period. In contrast, a significantly greater prevalence was found in the duloxetine cohort, wherein 571 subjects $(71.9 \%)$ had one or more potential DDIs $(P<0.0001$ for comparison to

Table 2 Patient Characteristics

\begin{tabular}{|c|c|c|c|c|c|}
\hline & \multicolumn{2}{|c|}{$\begin{array}{l}\text { Pregabalin } \\
N=794\end{array}$} & \multicolumn{2}{|c|}{$\begin{array}{l}\text { Duloxetine } \\
N=794\end{array}$} & \multirow[t]{2}{*}{$P$ value* } \\
\hline & $n$ & $\%$ & $n$ & $\%$ & \\
\hline Sex & & & & & 0.8577 \\
\hline Male & 180 & 22.7 & 183 & 23.0 & \\
\hline Female & 614 & 77.3 & 611 & 77.0 & \\
\hline Race/Ethnicity & & & & & 0.6976 \\
\hline White & 692 & 87.2 & 704 & 88.7 & \\
\hline Black & 76 & 9.6 & 67 & 8.4 & \\
\hline Hispanic & 13 & 1.6 & 14 & 1.8 & \\
\hline Other & 13 & 1.6 & 9 & 1.1 & \\
\hline Geographic Region & & & & & 0.9929 \\
\hline Northeast & 12 & 1.5 & 13 & 1.6 & \\
\hline Midwest & 187 & 23.6 & 185 & 23.3 & \\
\hline South & 531 & 66.9 & 534 & 67.3 & \\
\hline West & 64 & 8.1 & 62 & 7.8 & \\
\hline Low Income Status & 150 & 18.9 & 142 & 17.9 & 0.6043 \\
\hline \multirow[t]{2}{*}{ Dual Eligibility Status } & 93 & 11.7 & 97 & 12.2 & $0.757 \mid$ \\
\hline & Mean & SD & Mean & SD & \\
\hline Age, years & 62.9 & 12.6 & 62.4 & 12.0 & 0.3415 \\
\hline Propensity Score & 0.32 & 0.12 & 0.32 & 0.12 & 0.9582 \\
\hline
\end{tabular}

Notes: $*$ All $P$ values for categorical variables calculated using chi-square tests. All $P$ values for continuous variables calculated using Wilcoxon rank-sum tests. Abbreviation: SD, Standard Deviation.
Table 3 Preindex comorbid conditions

\begin{tabular}{|c|c|c|c|c|c|}
\hline & \multicolumn{2}{|c|}{$\begin{array}{l}\text { Pregabalin } \\
\mathrm{N}=794\end{array}$} & \multicolumn{2}{|c|}{$\begin{array}{l}\text { Duloxetine } \\
\mathrm{N}=794\end{array}$} & \multirow[t]{2}{*}{$P$ value* } \\
\hline & $\mathbf{n}$ & $\%$ & $\mathbf{n}$ & $\%$ & \\
\hline Abdominal pain/cramping & 228 & 28.7 & 223 & 28.1 & 0.7808 \\
\hline Anxiety disorder & 184 & 23.2 & 196 & 24.7 & 0.4803 \\
\hline Arthritis & 368 & 46.3 & 377 & 47.5 & 0.6509 \\
\hline $\begin{array}{l}\text { Back pain with neuropathic } \\
\text { involvement }\end{array}$ & 315 & 39.7 & 323 & 40.7 & 0.6822 \\
\hline $\begin{array}{l}\text { Causalgia and other painful } \\
\text { neuropathies }\end{array}$ & 211 & 26.6 & 210 & 26.4 & 0.9547 \\
\hline Depression & 247 & 31.1 & 243 & 30.6 & 0.828 \\
\hline Diabetes & 150 & 18.9 & 143 & 18.0 & 0.6507 \\
\hline Epilepsy & 20 & 2.5 & 23 & 2.9 & 0.6428 \\
\hline Fatigue & 278 & 35.0 & 277 & 34.9 & 0.958 \\
\hline Irritable bowel syndrome & 26 & 3.3 & 29 & 3.7 & 0.6806 \\
\hline Migraine headache & 59 & 7.4 & 58 & 7.3 & 0.9235 \\
\hline Muscle weakness & 62 & 7.8 & 54 & 6.8 & 0.4404 \\
\hline $\begin{array}{l}\text { Neck pain with } \\
\text { neuropathic involvement }\end{array}$ & 129 & 16.2 & 131 & 16.5 & 0.8921 \\
\hline Other back pain & 461 & 58.1 & 468 & 58.9 & 0.7215 \\
\hline Other mental disorders & 5 & 0.6 & 6 & 0.8 & 0.7622 \\
\hline Other musculoskeletal pain & 693 & 87.3 & 690 & 86.9 & 0.8224 \\
\hline Other neck pain (spinal) & 216 & 27.2 & 223 & 28.1 & 0.6945 \\
\hline Sleep disorders & 169 & 21.3 & 180 & 22.7 & 0.505 \\
\hline $\begin{array}{l}\text { Substance abuse or } \\
\text { dependence }\end{array}$ & 142 & 17.9 & 146 & 18.4 & 0.7945 \\
\hline Tension headache & 7 & 0.9 & 8 & 1.0 & 0.7953 \\
\hline Thinking/memory loss & 23 & 2.9 & 20 & 2.5 & 0.6428 \\
\hline Trigeminal nerve disorders & 7 & 0.9 & 14 & 1.8 & 0.1241 \\
\hline & Mean & SD & Mean & SD & \\
\hline Deyo-Charlson & 0.9 & 1.2 & 0.9 & 1.2 & 0.9188 \\
\hline
\end{tabular}

Notes: *All $P$ values for categorical variables calculated using chi-square tests. All $P$ values for continuous variables calculated using Wilcoxon rank-sum tests.

Abbreviation: SD, standard deviation.

pregabalin cohort). There were 41 potential DDIs involving pregabalin, all of which were of "major" severity. There were 1,377 potential DDIs involving duloxetine, including 23 "contraindicated" interactions and 1,083 "major" interactions (Table 4).

\section{Health care resource utilization}

The 6-month postindex all-cause health care utilization of the matched cohorts, segmented by the presence or absence of a potential DDI, is described in Table 5. There were no significant differences in any form of health care utilization between pregabalin subjects with and without a potential DDI. The same can be said for duloxetine, except that the mean number of visits per member for all-cause nonphysical therapy outpatient visits was significantly greater in duloxetine subjects with a potential DDI than those without a potential DDI (16.0 versus [vs] 13.0; $P=0.0009$ ). 
Table 4 Observed pregabalin and duloxetine drug-drug interactions by severity and interacting drug

\begin{tabular}{|c|c|c|}
\hline Severity* & Interacting drug & $\begin{array}{l}\text { Number of } \\
\text { interactions }\end{array}$ \\
\hline \multicolumn{3}{|l|}{ Pregabalin } \\
\hline Major & ketorolac & 4 \\
\hline Major & naproxen & 37 \\
\hline Total major for pre & & 41 \\
\hline Grand total for pre & & 41 \\
\hline \multicolumn{3}{|l|}{ Duloxetine } \\
\hline Contraindicated & metoclopramide & 22 \\
\hline Contraindicated & rasagiline & I \\
\hline \multicolumn{2}{|c|}{ Total contraindicated for duloxetine } & 23 \\
\hline Major & tramadol & 132 \\
\hline Major & trazodone & 118 \\
\hline Major & cyclobenzaprine & 88 \\
\hline Major & meloxicam & 86 \\
\hline Major & citalopram & 71 \\
\hline Major & clopidogrel & 62 \\
\hline Major & methadone & 60 \\
\hline Major & fluoxetine & 51 \\
\hline Major & Ibuprofen & 46 \\
\hline Major & escitalopram & 45 \\
\hline Major & sertraline & 44 \\
\hline Major & diclofenac & 40 \\
\hline Major & sumatriptan & 34 \\
\hline Major & paroxetine & 29 \\
\hline Major & celecoxib & 24 \\
\hline Major & naproxen & 23 \\
\hline Major & venlafaxine & 22 \\
\hline Major & nabumetone & 20 \\
\hline Major & etodolac & 15 \\
\hline Major & aspirin & 15 \\
\hline Major & piroxicam & 9 \\
\hline Major & lithium & 8 \\
\hline Major & indomethacin & 6 \\
\hline Major & cilostazol & 6 \\
\hline Major & milnacipran & 5 \\
\hline Major & flecainide & 4 \\
\hline Major & salsalate & 4 \\
\hline Major & oxaprozin & 3 \\
\hline Major & dipyridamole & 3 \\
\hline Major & ketorolac & 2 \\
\hline Major & zolmitriptan & 2 \\
\hline Major & sulindac & 2 \\
\hline Major & rizatriptan & 2 \\
\hline Major & ticlopidine & I \\
\hline Major & eletriptan & I \\
\hline \multicolumn{2}{|c|}{ Total major for duloxetine } & $\mathrm{I}, 083$ \\
\hline Moderate & amitriptyline & 81 \\
\hline Moderate & warfarin & 42 \\
\hline Moderate & promethazine & 38 \\
\hline Moderate & ciprofloxacin & 36 \\
\hline Moderate & tamsulosin & 21 \\
\hline Moderate & doxepin & 17 \\
\hline Moderate & nortriptyline & 11 \\
\hline Moderate & prochlorperazine & 6 \\
\hline Moderate & enoxaparin & 6 \\
\hline Moderate & imipramine & 5 \\
\hline
\end{tabular}

Table 4 (Continued)

\begin{tabular}{lll}
\hline Severity* & Interacting drug & $\begin{array}{l}\text { Number of } \\
\text { interactions }\end{array}$ \\
\hline Moderate & chlorpromazine & 3 \\
Moderate & perphenazine & 3 \\
Moderate & fluphenazine & 2 \\
Total moderate for duloxetine & $27 \mathrm{I}$ \\
Grand total for duloxetine & $\mathrm{I}, 377$ \\
\hline
\end{tabular}

Notes: *Severity category according to Micromedex 2.0 (Truven Health Analytics Inc.), as of May 31, 2013.

\section{Health care costs}

The 6-month postindex all-cause health care costs and component costs of the matched cohorts, segmented by the presence or absence of a potential DDI, are described in Table 6. There were no significant differences in all-cause health care costs, or component costs (eg, pharmacy), between pregabalin subjects with and without a potential DDI. Conversely, duloxetine subjects with a potential DDI exhibited significantly greater costs in comparison to duloxetine members without a potential DDI. Among duloxetine subjects, all-cause total health care costs were significantly higher for those with a potential DDI than those without $(\$ 9,373$ vs $\$ 7,228 ; P<0.0001)$. The component health care costs of total medical, outpatient-related, and total pharmacy costs were also significantly higher in duloxetine members with a potential DDI compared to those without a potential DDI.

\section{Model-adjusted health care costs}

A DID analysis was conducted to study the associations of index medication and mean all-cause health care costs (Table 7). No significant differences were found in modeladjusted mean all-cause health care costs for subjects with a potential DDI versus those members without a potential DDI in either the pregabalin cohort $(\$ 18,382$ vs $\$ 17,337$, respectively; $P=0.727)$ or the duloxetine cohort $(\$ 15,678$ vs $\$ 14,541$, respectively; $P=0.3124$ ). In accordance with those findings, the DID analysis found no significant difference in all-cause health care costs associated with the presence of a potential DDI attributable to the index medication $(P=0.8500)$.

\section{Opioid utilization and MEq}

The DID analyses for the associations of index medication with opioid utilization and MEq utilization are described in Tables 8 and 9, respectively. There was a trend toward a difference between pregabalin and duloxetine members in their respective pre- versus post-differences in presence of $\geq 1$ pharmacy claims for long-acting opioids $(1.6 \%$ and $3.4 \%$, 
Table 5 Six-month postindex all-cause health care utilization stratified by drug-drug interaction status

\begin{tabular}{|c|c|c|c|c|c|c|}
\hline & \multicolumn{3}{|l|}{ Pregabalin } & \multicolumn{3}{|l|}{ Duloxetine } \\
\hline & $\begin{array}{l}\text { No DDI present } \\
n=762\end{array}$ & $\begin{array}{l}\text { DDI present } \\
n=32\end{array}$ & $P$ value* & $\begin{array}{l}\text { No DDI present } \\
n=223\end{array}$ & $\begin{array}{l}\text { DDI present } \\
n=57 \mid\end{array}$ & $P$ value* \\
\hline \multicolumn{7}{|l|}{ All-cause inpatient visits } \\
\hline Members with hospitalization, $\mathrm{n}(\%)$ & $160(21.0)$ & $7(21.9)$ & 0.905 & $4 \mathrm{I}(18.4)$ & II 8 (20.7) & 0.4706 \\
\hline Hospitalizations per member, mean (SD) & $0.4(1.7)$ & $0.4(0.9)$ & 0.8637 & $0.4(1.4)$ & $0.5(1.8)$ & 0.4578 \\
\hline \multicolumn{7}{|l|}{ All-cause emergency room visits } \\
\hline Members with visit, $\mathrm{n}(\%)$ & $200(26.2)$ & $10(31.3)$ & 0.5296 & $54(24.2)$ & $164(28.7)$ & 0.2010 \\
\hline Visits per member, mean (SD) & $0.5(\mathrm{I} .3)$ & $0.5(0.8)$ & 0.6506 & $0.5(\mathrm{I} .2)$ & $0.6(1.4)$ & 0.1886 \\
\hline \multicolumn{7}{|l|}{ All-cause outpatient visits (nonphysical therapy) } \\
\hline Members with visit, n (\%) & $752(98.7)$ & $32(100.0)$ & 0.5143 & $220(98.7)$ & $566(99.1)$ & 1.0 \\
\hline Visits per member, mean (SD) & $15.5(10.2)$ & $19.2(12.7)$ & 0.0943 & $13.0(8.5)$ & $16.0(10.8)$ & 0.0009 \\
\hline \multicolumn{7}{|l|}{ All-cause physical therapy visits } \\
\hline Members with visit, $\mathrm{n}(\%)$ & $123(16.1)$ & $7(2 \mid .9)$ & 0.3905 & $37(16.6)$ & $85(14.9)$ & 0.5492 \\
\hline Visits per member, mean (SD) & $0.9(3.3)$ & I.5 (4.0) & 0.3359 & $0.9(3.5)$ & $0.6(2.5)$ & 0.4887 \\
\hline
\end{tabular}

Notes: *All $P$ values for categorical variables calculated using chi-square tests. All $P$ values for continuous variables calculated using Wilcoxon rank-sum tests.

Abbreviations: DDI, potential drug-drug interaction; SD, standard deviation.

respectively; $P=0.077$ ). The DID analysis of preindex and postindex MEq revealed no significant difference associated with the index medication.

\section{Discussion}

The current study adds to the limited knowledge regarding the real-world impact of newly initiated pregabalin or duloxetine treatment on FM patients' encounters with potential DDIs, the health care cost and utilization consequences of those interactions, and on opioid utilization.

The results show that the prevalence of potential pregabalin DDIs was markedly lower than that of potential duloxetine DDIs. This finding is not surprising given the respective metabolic pathways that these two drugs follow and the comorbidity burden and polypharmacy risk common to FM. While pregabalin has minimal pharmacokinetic or pharmacodynamic interactions with other medications, duloxetine's hepatic metabolism by and inhibition of cytochrome P-450 (CYP450) isoenzymes
2D6 and 1A2 and its high level of plasma protein binding result in many potential DDIs with other medications. ${ }^{29,30}$

The substantial burden of comorbid conditions found in the matched pregabalin and duloxetine cohorts, and the medications used for treatment of those conditions, align with previous studies of FM patients ${ }^{31-33}$ and play a major role in the observed potential DDI prevalence. Studies of other chronic pain conditions have found that patients receiving treatment for pain are at increased risk for exposure to potential DDIs compared to those patients not being treated for those conditions. ${ }^{34,35}$ A recent study, while in a predominantly commercially insured diabetic peripheral neuropathy (DPN) population, substantiates the findings of the present study. Specifically, Johnston et $\mathrm{al}^{36}$ found the frequency of potential contraindicated, major, and moderate DDIs in DPN patients newly initiated on duloxetine to be $3.9 \%, 36.9 \%$, and $33.8 \%$, respectively. Conversely, no DPN patients newly initiated on pregabalin encountered a potential DDI of any severity.

Table 6 Six-month postindex all-cause health care costs and component costs stratified by drug-drug interaction status

\begin{tabular}{|c|c|c|c|c|c|c|}
\hline & \multicolumn{3}{|l|}{ Pregabalin } & \multicolumn{3}{|l|}{$\underline{\text { Duloxetine }}$} \\
\hline & $\begin{array}{l}\text { No DDI present } \\
n=762\end{array}$ & $\begin{array}{l}\text { DDI present } \\
n=32\end{array}$ & $P$ value* & $\begin{array}{l}\text { No DDI present } \\
n=223\end{array}$ & $\begin{array}{l}\text { DDI present } \\
n=57 \text { I }\end{array}$ & $P$ value* \\
\hline All-cause total health care costs, mean (SD) & $9,089(12,064)$ & II,896 (|4,78I) & 0.3974 & 7,228 ( I I,389) & $9,373(13,022)$ & $<0.0001$ \\
\hline All-cause total medical costs, mean (SD) & $6,559(11,539)$ & $9,304(14,391)$ & 0.427 & $5,480(I 1,23 I)$ & $6,532(11,488)$ & 0.0082 \\
\hline $\begin{array}{l}\text { Outpatient-related (nonphysical } \\
\text { therapy), mean (SD) }\end{array}$ & $2,651(3,950)$ & $2,929(2,618)$ & 0.2273 & $\mathrm{I}, 946(2,408)$ & $2,476(3,552)$ & 0.002 \\
\hline Physical therapy-related, mean (SD) & $112(442)$ & $144(342)$ & 0.339 & $98(405)$ & $79(318)$ & $0.74 I I$ \\
\hline Inpatient-related, mean (SD) & $2,876(9,269)$ & $5,078(1 \mathrm{I}, 656)$ & 0.6729 & $2,656(9,54 I)$ & $2,985(9,460)$ & 0.5224 \\
\hline ER-related, mean (SD) & $304(9,001)$ & 205 (390) & 0.6413 & $239(612)$ & 351 (99I) & 0.1900 \\
\hline All-cause total pharmacy costs, mean (SD) & $2,529(3,04 I)$ & $2,591(2,872)$ & 0.7218 & $\mathrm{I}, 748(\mathrm{I}, 603)$ & $2,84 \mid(5,476)$ & $<0.0001$ \\
\hline
\end{tabular}

Notes: All costs are in US dollars. *All $P$ values for categorical variables calculated using chi-square. All $P$ values for continuous variables calculated using Wilcoxon rank-sum tests.

Abbreviations: DDI, potential drug-drug interaction; SD, standard deviation. 
Table 7 Model-based* 6-month postindex all-cause total health care costs by index medication and DDI status and difference-in-difference comparison between pregabalin and duloxetine

\begin{tabular}{lll}
\hline & \multicolumn{2}{l}{ All-cause health care costs } \\
\cline { 2 - 3 } & Mean & $\begin{array}{l}\mathbf{9 5 \%} \text { confidence } \\
\text { interval }\end{array}$ \\
\hline $\begin{array}{ll}\text { Pregabalin } \\
\text { No DDI present }\end{array}$ & $\$ 17,337$ & $\$ 10,322-\$ 29,118$ \\
DDI present & $\$ 18,382$ & $\$ 9,959-\$ 33,930$ \\
Difference** & $\$ 1,045$ & - \\
$\quad P$ value & 0.727 & - \\
Duloxetine & & \\
No DDI present & $\$ 14,541$ & $\$ 8,499-\$ 24,878$ \\
DDI present & $\$ 15,678$ & $\$ 9,368-\$ 26,239$ \\
Difference** & $\$ 1,137$ & - \\
$P$ value & 0.3124 & - \\
Difference-in-difference & $\$ 1,045$ versus $\$ 1,137$ \\
comparison & $P=0.8500$ & \\
\hline
\end{tabular}

Notes: *GLMM model with gamma distribution and log link. Model-based means, standard errors, and confidence intervals were derived from model and transformed into dollar values through exponentiation. All $P$ values are calculated using Wald chi square tests through LSMEANS option. Presence of potential DDI, drug used (duloxetine versus pregabalin), DDI*Drug interaction term, baseline demographic characteristics, baseline comorbidities present, and preindex medication utilization controlled for in GLMM model; **represents the additional health care costs associated with the presence of a potential DDI.

Abbreviations: DDI, potential drug-drug interaction; GLMM, generalized linear mixed model; LSMEANS, least square means.

Previous research reported no statistically significant differences in postinitiation costs for FM patients newly initiated on pregabalin or duloxetine. ${ }^{31,33}$ While not an objective of this study, newly initiated pregabalin subjects were found to have higher absolute pre- and postindex all-cause health care costs

Table 8 Opioid utilization* in 6-month pre- and postindex periods and difference-in-difference comparison between pregabalin and duloxetine

\begin{tabular}{|c|c|c|c|}
\hline & $\begin{array}{l}\text { Long-acting } \\
\text { opioids }\end{array}$ & $\begin{array}{l}\text { Short-acting less } \\
\text { potent opioids }\end{array}$ & $\begin{array}{l}\text { Short-acting more } \\
\text { potent opioids }\end{array}$ \\
\hline & $\%$ & $\%$ & $\%$ \\
\hline \multicolumn{4}{|l|}{ Pregabalin } \\
\hline Preindex & 15.4 & 60.8 & 22.7 \\
\hline Postindex & 17.0 & 62.2 & 25.1 \\
\hline Difference & +1.6 & +1.4 & +2.4 \\
\hline \multicolumn{4}{|l|}{ Duloxetine } \\
\hline Preindex & 14.5 & 60.2 & 23.4 \\
\hline Postindex & 17.9 & 59.4 & 25.6 \\
\hline Difference & +3.4 & -0.8 & +2.1 \\
\hline $\begin{array}{l}\text { Difference-in- } \\
\text { difference } \\
\text { comparison** }\end{array}$ & I. 6 vs 3.4 & I. .4 vs -0.8 & 2.4 vs 2.1 \\
\hline $\begin{array}{l}\text { Statistical } \\
\text { difference** }\end{array}$ & $\begin{array}{l}t=-1.77 \\
P=0.077\end{array}$ & $\begin{array}{l}t=0.80 \\
P=0.424\end{array}$ & $\begin{array}{l}t=0.04 \\
P=0.970\end{array}$ \\
\hline
\end{tabular}

Notes: *Defined as one or more opioid prescription fills during period; $* *$ differencein-difference $t$-statistic derived from a generalized linear mixed model with a logit link and binary distribution, adjusting for baseline demographics, Deyo-Charlson Comorbidity Index, and pre- and postindex nonopioid pain medication utilization. Abbreviations: vs, versus.
Table 9 Morphine equivalents utilization in pre- and postindex 6-month periods and difference-in-difference comparison between pregabalin and duloxetine

\begin{tabular}{|c|c|c|}
\hline & \multicolumn{2}{|c|}{$\begin{array}{l}\text { Morphine equivalents } \\
\text { milligrams/30 days }\end{array}$} \\
\hline & Mean & $\begin{array}{l}\text { Standard } \\
\text { deviation }\end{array}$ \\
\hline \multicolumn{3}{|l|}{ Pregabalin } \\
\hline Preindex & 930.6 & $2,300.9$ \\
\hline Postindex & $\mathrm{I}, 070.2$ & $2,609.7$ \\
\hline Difference & 139.6 & $\mathrm{I}, 245.3$ \\
\hline \multicolumn{3}{|l|}{ Duloxetine } \\
\hline Preindex & 968.0 & $2,294.2$ \\
\hline Postindex & $\mathrm{I}, 149.4$ & $2,549.6$ \\
\hline Difference & 181.3 & $\mathrm{I}, 384.4$ \\
\hline Difference-in-difference & 139.6 versus 181.3 & \\
\hline comparison* & $t=-0.63, P=0.528$ & \\
\hline
\end{tabular}

Notes: *Difference-in-difference $t$-statistic derived from a generalized linear mixed model with an identity link and a Gaussian distribution, adjusting for baseline demographics, Deyo-Charlson Comorbidity Index, and pre- and postindex nonopioid pain medication utilization.

than newly initiated duloxetine subjects. The present study endeavored to determine the impact of potential pregabalin and duloxetine DDIs on 6-month postinitiation costs. Among duloxetine subjects, mean all-cause total health care costs, total medical, outpatient-related, and total pharmacy costs were significantly higher for those with a potential DDI than those without a potential DDI. Nonstatistically significant cost increases were found between the pregabalin members with and without a potential DDI. Furthermore, the modelbased analysis found no significant difference between the all-cause health care costs increases observed in both the pregabalin DDI group (vs pregabalin with no DDI) and the duloxetine DDI group (vs duloxetine with no DDI).

The nonsignificant findings for within-pregabalin cohort comparisons and the DID analysis must be tempered by the small number of pregabalin subjects with a potential DDI $(n=32)$. However, the statistically significant increase in costs associated with potential DDIs within the duloxetine cohort cannot be overlooked. While causality cannot be assigned to the presence of DDIs alone within the duloxetine cohort in the present study, other studies of chronic pain conditions have found that CYP450 interactions between specific opioids (codeine, fentanyl, hydrocodone, methadone, oxycodone, and tramadol) and concomitant medications that serve as substrates or inhibitors of CYP450 isoenzymes 3A4 and 2D6, the latter of which includes duloxetine, result in higher costs and greater health care utilization. ${ }^{37-39}$

One such study, a retrospective analysis of 170,086 patients using claims data from 2004 to 2008, found 
significantly higher mean total 6-month costs in noncancer, chronic pain subjects with an exposure to a potential DDI compared to matched subjects without an exposure ( $\$ 8,165$ vs $\$ 7,498$, respectively; $P<0.01) .{ }^{37}$ This same study found that potential DDI exposed patients versus nonexposed patients experienced significantly more office visits (19.10 vs $18.29 ; P<0.01$ ), outpatient visits (6.71 vs $6.39 ; P<0.01$ ), emergency department visits ( 0.46 vs $0.43 ; P<0.01)$, and inpatient hospitalizations $(0.13$ vs $0.12 ; P<0.01) .{ }^{36}$ While these overpowered statistically significant differences may be difficult to interpret in terms of absolute clinical relevance, the increase in health care utilization in the presence of potential DDI exposure is directionally consistent. The only significant, albeit directionally consistent, finding in the present study regarding health care utilization was an increase in all-cause, nonphysical therapy outpatient visits for duloxetine members exposed to a potential DDI.

Changes in opioid utilization after initiation of pregabalin or duloxetine were also assessed in the present study. Previous retrospective studies across various patient populations and utilizing disparate definitions of opioid utilization have incongruent findings regarding the opioid-sparing effect of pregabalin ${ }^{31,40,41}$ and duloxetine. ${ }^{31,42}$ In the lone head-to-head retrospective analysis of these drugs in a FM population, no changes in pre- to postinitiation of long-acting, short-acting, strong opioid, weak opioid, or any opioid use were found for pregabalin. ${ }^{31}$ These findings held for duloxetine with the exception of a decrease in weak opioid use from pre- to postinitiation periods ( $55.1 \%$ vs $49.3 \%$, respectively; $P=0.0027$ ), as defined by the percentage of patients with one or more pharmacy claims for those categories of opioids. The present study found no difference between pregabalin and duloxetine members in their respective pre- versus post- differences in the percentage of members with $\geq 1$ pharmacy claims for long-acting opioids, short-acting more potent, or short-acting less potent. A robust DID analysis of preindex and postindex MEq used also revealed no significant difference between pregabalin and duloxetine.

As with all studies involving administrative claims data, several limitations must be noted. The use of secondary data is limited by the threat of validity posed by missing, incomplete, or inaccurate data within health care information technology systems as well as by provider, region, or site-specific coding and documentation practices. The use of paid pharmacy claims as a proxy for actual medication consumption cannot assess the true medication-taking behavior of patients nor capture the use of over-the-counter medications or remedies impactful to the disease state in question. It is possible that patients may have discontinued a preindex interacting agent even though the days' supply of the interacting agent overlapped the index date. Patient medication behavior after initiation of index drug and switching or discontinuation of the index drug after the index prescription fill was not assessed. Indirect costs were not considered as part of this study. The observational nature of this study cannot assign a causal effect. Although PS matching and multivariate modeling attempted to control for potential confounding, these approaches can only reduce bias resulting from only covariates included in the statistical models. Even so, residual confounding from those covariates can still occur. More serious, full-fledged confounding from unknown or unmeasured covariates (eg, severity of FM) remains a possibility. Lastly, actual clinical harm due to the presence of a potential DDI was not assessed.

\section{Conclusion}

The results of this retrospective analysis suggest that the realworld prevalence of potential duloxetine DDIs in a MAPD population is substantially greater than that of potential pregabalin DDIs. While the low prevalence of potential pregabalin DDIs is desirable, it places limits on the ability or sensitivity to assess the impact of those DDIs on health care utilization and costs within-cohort or across comparator drugs. The significantly higher prevalence of DDIs and potential cost impact found in FM duloxetine users, relative to pregabalin users, underscore the importance of considering DDIs when selecting a treatment.

\section{Acknowledgments}

The authors wish to thank Mary Costantino at Comprehensive Health Insights Inc. for assistance with preparation of this manuscript. This research was conceived, funded, and carried out collaboratively by Humana Inc., Pfizer Inc., and Competitive Health Analytics Inc. The research concept was approved by the Joint Research Governance Committee of the Humana-Pfizer Research Collaboration, comprised of Humana Inc. and Pfizer Inc. employees, and plans to publish results were made known prior to commencing the study.

\section{Disclosure}

JJE and BTS are employees of Competitive Health Analytics Inc., a wholly owned subsidiary of Humana Inc. CRB is an employee of Humana Inc. BTS is a stockholder of Humana Inc. Competitive Health Analytics Inc. received funding support from Pfizer Inc. in connection with conducting this study and for the development of this article. ABS, JCC, and 
$\mathrm{BP}$ are employees and stockholders of Pfizer Inc. At the time that this research was conducted, LLTE was an employee of Competitive Health Analytics Inc. The authors report no further conflicts of interest with this work.

\section{References}

1. Goldenberg DL, Bradley LA, Arnold LM, Glass JM, Clauw DJ. Understanding fibromyalgia and its related disorders. Prim Care Companion J Clin Psychiatry. 2008;10(2):133-144.

2. Mease P. Fibromyalgia syndrome: review of clinical presentation, pathogenesis, outcome measures, and treatment. J Rheumatol Suppl. 2005;75:6-21.

3. Vincent A, Lahr BD, Wolfe F, et al. Prevalence of fibromyalgia: a population-based study in Olmsted County, Minnesota, utilizing the Rochester Epidemiology Project. Arthritis Care Res (Hoboken). 2013;65(5):786-792.

4. Adams EH, Daniel S, Chandran AB, et al. A population-based survey and physician assessment of the characteristics and prevalence of fibromyalgia. Presented at the American College of Rheumatology Annual Meeting; October 25-30, 2013; San Diego, CA.

5. Yunus MB, Inanici F, Aldag JC, Mangold RF. Fibromyalgia in men: comparison of clinical features with women. J Rheumatol. 2000;27(2): 485-490.

6. Staud R. Pharmacological treatment of fibromyalgia syndrome: new developments. Drugs. 2010;70(1):1-14.

7. Wierwille L. Fibromyalgia: diagnosing and managing a complex syndrome. J Am Acad Nurse Pract. 2012;24(4):184-192.

8. Arendt-Nielsen L, Graven-Nielsen T. Central sensitization in fibromyalgia and other musculoskeletal disorders. Curr Pain Headache Rep. 2003;7(5):355-361.

9. Yunus MB. Symptoms and signs of fibromyalgia syndrome: an overview. In: Wallace DJCD, editor. Fibromyalgia and Other Central Pain Syndromes. Philadelphia, PA: Lippincott, Williams \& Wilkins, 2005;125-132.

10. Bennett RM. Clinical manifestations and diagnosis of fibromyalgia. Rheum Dis Clin North Am. 2009;35(2):215-232.

11. Wolfe F, Clauw DJ, Fitzcharles MA, et al. The American College of Rheumatology preliminary diagnostic criteria for fibromyalgia and measurement of symptom severity. Arthritis Care Res (Hoboken). 2010;62(5):600-610.

12. Weir PT, Harlan GA, Nkoy FL, et al. The incidence of fibromyalgia and its associated comorbidities: a population-based retrospective cohort study based on International Classification of Diseases, 9th Revision codes. J Clin Rheumatol. 2006;12(3):124-128.

13. Abeles AM, Pillinger MH, Solitar BM, Abeles M. Narrative review: the pathophysiology of fibromyalgia. Ann Intern Med. 2007;146(10): 726-734.

14. Abeles M, Solitar BM, Pillinger MH, Abeles AM. Update on fibromyalgia therapy. Am J Med. 2008;121(7):555-561.

15. Goldenberg DL, Burckhardt C, Crofford L. Management of fibromyalgia syndrome. JAMA. 2004;292(19):2388-2395.

16. Carville SF, Arendt-Nielsen S, Bliddal H, et al; EULAR. EULAR evidence-based recommendations for the management of fibromyalgia syndrome. Ann Rheum Dis. 2008;67(4):536-541.

17. Fitzcharles MA, Ste-Marie PA, Goldenberg DL, et al; National Fibromyalgia Guideline Advisory Panel. 2012 Canadian Guidelines for the diagnosis and management of fibromyalgia syndrome: executive summary. Pain Res Manag. 2013;18(3):119-126.

18. Sommer C, Häuser WH, Alten R, et al. Drug therapy of fibromyalgia syndrome. systematic review, meta-analysis and guideline. Schmerz. 2012;26(3):297-310. German.

19. Ablin JN, Amital H, Ehrenfeld M, et al; Israeli Rheumatology Association. [Guidelines for the diagnosis and treatment of the fibromyalgia syndrome]. Harefuah. 2013;152(12):742-747, 750-751. Hebrew.

20. Painter JT, Crofford LJ. Chronic opioid use in fibromyalgia syndrome: a clinical review. J Clin Rheumatol. 2013;19(2):72-77.
21. Häuser W, Petzke F, Sommer C. Comparative efficacy and harms of duloxetine, milnacipran, and pregabalin in fibromyalgia syndrome. J Pain. 2010;11(6):505-521.

22. Deyo RA, Cherkin DC, Ciol MA. Adapting a clinical comorbidity index for use with ICD-9-CM administrative databases. J Clin Epidemiol. 1992;45(6):613-619.

23. Klabunde CN, Potosky AL, Legler JM, Warren JL. Development of a comorbidity index using physician claims data. J Clin Epidemiol. 2000;53(12):1258-1267.

24. Von Korff M, Saunders K, Thomas RG, et al. De facto long-term opioid therapy for non-cancer pain. Clin J Pain. 2008;24(6):521-527.

25. Rosenbaum PR, Rubin DB. The central role of the propensity score in observational studies for causal effects. Biometrika. 1983;70(1):41-55.

26. D'Agostino RB. Propensity score methods for bias reduction in the comparison of a treatment to a non-randomized control group. Stat Med. 1998;17(19):2265-2281.

27. Rosner B. Fundamentals of Biostatistics. Seventh edition. Boston, MA: Brooks/Cole Cengage Learning; 2010.

28. Jones AM, Rice N, Bago d'Uva T, Balia S. Applied Health Economics. Second edition. New York, NY: Routledge; 2013.

29. Lyrica (pregabalin) package insert. New York: Pfizer Inc.; 2013.

30. Cymbalta (duloxetine) package insert. Indianapolis: Eli Lilly and Company; 2012.

31. Gore M, Tai KS, Chandran A, Zlateva G, Leslie D. Clinical comorbidities, treatment patterns, and healthcare costs among patients with fibromyalgia newly prescribed pregabalin or duloxetine in usual care. J Med Econ. 2012;15(1):19-31.

32. Kim SC, Landon JE, Solomon DH. Clinical characteristics and medication uses among fibromyalgia patients newly prescribed amitriptyline, duloxetine, gabapentin, or pregabalin. Arthritis Care Res (Hoboken). 2013;65(11):1813-1819.

33. Burke JP, Sanchez RJ, Joshi AV, Cappelleri JC, Kulakodlu M, Halpern R. Health care costs in patients with fibromyalgia on pregabalin vs duloxetine. Pain Pract. 2012;12(1):14-22.

34. Pergolizzi JV, Labhsetwar SA, Puenpatom RA, Joo S, Ben-Joseph RH, Summers KH. Prevalence of exposure to potential CYP450 pharmacokinetic drug-drug interactions among patients with chronic low back pain taking opioids. Pain Pract. 2011;11(3):230-239.

35. Pergolizzi JV, Labhsetwar SA, Puenpatom RA, Joo S, Ben-Joseph R, Summers KH. Exposure to potential CYP450 pharmacokinetic drugdrug interactions among osteoarthritis patients: incremental risk of multiple prescriptions. Pain Pract. 2011;11(4):325-336.

36. Johnston SS, Udall M, Cappelleri JC, et al. Cost comparison of drugdrug and drug-condition interactions in patients with painful diabetic peripheral neuropathy treated with pregabalin versus duloxetine. Am J Health Syst Pharm. 2013;70(24):2207-2217.

37. Summers KH, Puenpatom RA, Rajan N, Ben-Joseph R, Ohsfeldt R. Economic impact of potential drug-drug interactions in opioid analgesics. J Med Econ. 2011;14(4):390-396.

38. Pergolizzi JV, Labhsetwar SA, Amy Puenpatom R, Ben-Joseph R, Ohsfeldt R, Summers KH. Economic impact of potential CYP450 pharmacokinetic drug-drug interactions among chronic low back pain patients taking opioids. Pain Pract. 2012;12(1):45-56.

39. Pergolizzi JV, Labhsetwar SA, Puenpatom RA, Ben-Joseph R, Ohsfeldt R, Summers KH. Economic impact of potential drug-drug interactions among osteoarthritis patients taking opioids. Pain Pract. 2012;12(1):33-44.

40. Gore M, Sadosky A, Tai KS, Stacey B. A retrospective evaluation of the use of gabapentin and pregabalin in patients with postherpetic neuralgia in usual-care settings. Clin Ther. 2007;29(8):1655-1670.

41. Gore M, Tai KS, Zlateva G, Bala Chandran A, Leslie D. Clinical characteristics, pharmacotherapy, and healthcare resource use among patients with diabetic neuropathy newly prescribed pregabalin or gabapentin. Pain Pract. 2011;11(6):528-539.

42. Wu N, Chen SY, Hallett LA, et al. Opioid utilization and health-care costs among patients with diabetic peripheral neuropathic pain treated with duloxetine vs other therapies. Pain Pract. 2011;11(1):48-56. 


\section{Publish your work in this journal}

ClinicoEconomics \& Outcomes Research is an international, peerreviewed open-access journal focusing on Health Technology Assessment, Pharmacoeconomics and Outcomes Research in the areas of diagnosis, medical devices, and clinical, surgical and pharmacological intervention. The economic impact of health policy and health systems organization also constitute important areas of coverage. The manuscript management system is completely online and includes a very quick and fair peer-review system, which is all easy to use. Visit http://www.dovepress.com/testimonials.php to read real quotes from published authors.

Submit your manuscript here: http://www.dovepress.com/clinicoeconomics-and-outcomes-research-journal 